\title{
La responsabilidad institucional de la Iglesia Católica por los abusos sexuales de su sacerdote (Corte de Apelaciones de Santiago)
}

\author{
Comentario de Pablo Carvacho Traverso*
}

Santiago, 27 de marzo de 2019.

1. Inicio de la prescripción.

"Decimonoveno: Teniendo la acción indemnizatoria por objetivo esencial, la reparación del daño y que como se viene desarrollando, el término legal del artículo 2332 del Código Civil, ha de computarse desde que concurran todos los elementos del ilícito civil, ha de concluirse lógica y racionalmente que el tiempo al que hace referencia tal disposición, principia en el caso de autos desde el envió de los antecedentes a la Congregación para la Doctrina de la Fe, esto es en junio de 2010, época en que cesó la inactividad del Arzobispado”.

2. El conocimiento de los hechos y la inactividad por parte de la Iglesia Católica y su jerarquía como presunción del daño de las víctimas.

"Cuadragésimo Segundo: los demandantes han sido dañados por la Iglesia en su condición de ser humano, al contribuir a la traumatización acumulativa de su psique intrínseca, provocando un efecto devastador en su condición de tal, atendido los antecedentes consignados en dicho instrumento y referidos a que las víctimas buscaron divulgar el abuso mediante denuncias y no fueron escuchadas, resultando que esa divulgación constituía una amenaza para el círculo cercano, para la imagen pública del abusador y para el prestigio de la Iglesia Católica como institución, como ocurre con frecuencia en los casos de abuso sexual dentro de una familia, la situaciones desmentida y negada y la denuncia es desacreditada, debiendo exponer su privacidad para romper el circuito de abuso y silencio, además, que la negligencia en la investigación del abuso que se hizo desde las instancias oficiales de la Iglesia Católica tuvo gran impacto sobre las víctimas cuando las autoridades institucionales descartaron la denuncia en lugar de

* Licenciado en Ciencias Jurídicas y Sociales, Universidad de Chile. Abogado. Magíster en Sociología, Pontificia Universidad Católica de Chile. Magíster en Ciencias del Derecho, Universidad de Stanford, Estados Unidos. Subdirector del Centro Justicia y Sociedad y Profesor del Instituto de Sociología, Pontificia Universidad Católica de Chile. Correo electrónico: pacarvac@uc.cl 
considerar la posibilidad de examinar si tenía algún elemento de verdad, protegiendo con su inactividad a los abusadores como si ellos fueran víctimas de una infamia y agresión pública contra su buen nombre y descuidando por completo lo ocurrido a las víctimas del abuso...".

3. Reconoce jurídicamente a la Iglesia Católica chilena y su representación en el Obispo de Santiago.

"Vigésimo Sexto: Que, resulta indiscutible que la Iglesia Católica en Chile o chilena goza, en el ámbito jurídico interno, de personalidad jurídica de derecho público, de lo anterior se sigue inevitablemente que, como tal, es capaz de ejercer derechos y contraer obligaciones civiles, y de ser representada judicial y extrajudicialmente, según lo prescribe el artículo 545 del Código Civil, el que sólo excluye, en el caso de las Iglesias y conforme lo precisa el inciso $2^{\circ}$ del artículo 547 del mismo Código, al Título XXXIII, del Libro I que regula su forma de constitución, orden u organización interna, formas de disolución u otras allí regladas, las que se rigen por leyes y reglamentos especiales”.

"Vigésimo SÉPtimo: Que, la responsabilidad civil sea individual y no pueda, en consecuencia, hacerse responsable a la Iglesia Católica en Chile, particularmente en la persona y bienes de quien la representa, el Arzobispado de Santiago, de los ilícitos civiles cometidos por consagrados o, fieles laicos o no que se encuentren bajo su vigilancia, no resulta admisible en el orden civil interno, como tampoco parece serlo en el orden canónico conforme se desprende de la lectura del canon $1284, \S 2,3^{\circ}$ que señala, en materia de administración de los bienes de la Iglesia, que "A no ser que le haya reportado un provecho, y en la medida del mismo, la persona jurídica no está obligada a responder de los actos realizados inválidamente por los administradores; pero de los actos que éstos realizan ilegítima pero válidamente, responderá la misma persona jurídica, sin perjuicio del derecho de acción o de recurso de la misma contra los administradores que le hubieran causado daños.", de manera que no resulta descartable la aplicación de las presunciones de culpabilidad para hacer efectiva su responsabilidad por el hecho ajeno".

4. Establece la responsabilidad de la Iglesia Católica chilena por el hecho propio.

“Trigésimo Nono: Que, como se ha establecido en autos, la Iglesia actuó con desidia en la investigación de las denuncias y en el amparo y protección de las víctimas..."

Trigésimo Quinto: “sabiendo a través de su Cardenal Errázuriz, sobre los abusos descritos en la causa penal e informes de los promotores de Justicia, no entregó tratamiento sicológico ni siquiátrico u otra forma de amparo a las víctimas y, por el contrario, permitiendo que Karadima Fariña aumentara la intensidad y frecuencia de aquellos, fue felicitado y objeto de agradecimientos por su labor en la parroquia El Bosque, lugar en que vivió con el beneplácito de la demandada al menos 5 años más, además, nombrándose como sucesor del victimario a su colaborador cercano Juan Esteban Morales, todo ello luego de aceptar su renuncia por razones de edad”. 
"Cuadragésimo Quinto: Que, las conclusiones que se vienen expresando acerca de las omisiones y errores de la cúpula de la Iglesia Católica, que, en concepto de esta Corte, se demuestra que la demandada ha sido negligente en su proceder en términos tales que pueden ser calificados como propios de un encubrimiento que da origen a la configuración de un ilícito civil."

"Quincuagésimo Tercero: Que, en concordancia con lo expresado en los razonamientos anteriores, en el caso que nos ocupa el daño moral resulta manifiesto, pero es preciso consignar que el que se debe indemnizar está referido exclusivamente al hecho propio de la Iglesia”

5. Establece la posibilidad de accionar contra la Iglesia Católica por los hechos de su dependiente.

"Vigésimo Sexto: La responsabilidad civil de la persona jurídica de derecho público, Iglesia Católica en Chile o chilena, y de las autoridades que la representan pasa, en un sentido amplio, por el reproche que pueda hacérsele a la traición a la confianza legítima que sus fieles han depositado en ellas de que, por un lado, cumplirán diligentemente su oficio como garantes del mensaje que condena los atentados a la dignidad de la persona humana y, por otro, la seguridad que les entrega la prescripción de los superiores de una diócesis de velar por la obediencia y observancia por los inferiores de este mensaje en el ejercicio de sus ministerios. De ahí que no resulta discutible la autoridad que ejerce, independientemente de las prescripciones canónicas, el obispo respecto de los sacerdotes de su diócesis, relación de autoridad que, en relación a sus respectivas funciones, le permite dar órdenes de cómo actuar o qué comportamientos observar frente a determinados hechos que producen efectos o se materializan en la vida secular durante el ejercicio de sus funciones".

“Considerando Vigésimo Octavo: De ahí que sea posible concluir que todos los actos temporales o seculares en el orden civil de los obispos son actos de la persona jurídica Iglesia Católica chilena. Particularmente, la dirección y vigilancia de los sacerdotes y el ejercicio de la disciplina y la observancia de las reglas de respeto de la persona humana sean fieles o no de su jurisdicción territorial. Si un sacerdote, entonces, no observa la conducta debida e infiere daño en la persona de otro en el cumplimiento de sus obligaciones, la Iglesia es directamente responsable por no haber observado o ejercicio correctamente su deber de vigilancia debida".

\section{COMENTARIO}

El fallo de 27 de marzo de 2019 de la Corte de Apelaciones respecto de la sentencia de primera instancia de 16 de marzo del 2017 del Ministro de fuero Juan Muñoz Pardo respecto del caso de responsabilidad extracontractual de la Iglesia por los abusos 
sistemáticos por parte del sacerdote Fernando Karadima a distintas víctimas, constituye un fallo histórico, con importantes implicancias jurisprudenciales, institucionales y sociales. La sentencia que se comenta no fue objeto de posteriores recursos y se encuentra actualmente ejecutoriada.

I. En primer lugar, el fallo afianza un consenso doctrinario respecto de que el inicio del cómputo de la prescripción comienza con la manifestación del daño. Esta argumentación de la Corte de Apelaciones es uno de los puntos más importantes de la sentencia en tanto reconoce jurisprudencialmente la dinámica inherente de los abusos sexuales cometidos contra niños, niñas y adolescentes. En efecto, en estos casos operan técnicas de neutralización del delito en el que los abusadores logran invisibilizar los abusos cometidos. ${ }^{1}$ Para ello, si bien en un principio los victimarios niegan cualquier tipo de responsabilidad, cuando los hechos se hacen evidentes, rechazan que los hechos importen un daño a la víctima. Luego, buscan anular a la víctima, culpabilizándola de los actos, para finalmente buscar la condena social de ellas mediante la difamación respecto de sus defectos, personalidad o estatus moral. Este proceso, que es propio de los abusos de sacerdotes en el contexto de la Iglesia Católica, se ve reforzada por ciertos "inhibidores" de la develación que operan en cualquier abuso en que están involucrados menores de edad. ${ }^{2}$ Entre estos, es posible mencionar la edad e inmadurez de las víctimas, lo que les impide reconocer el valor social y normativo de los abusos sufridos; la falta de habilidades y herramientas para entender y comunicar lo vivido; el sentimiento de culpa y peligro de sus seres cercanos frente a la develación, entre otras razones que terminan impidiendo la develación de los abusos.

La consecuencia de lo anterior es que la mayoría de los niños y niñas no develan su victimización si no luego de meses o años desde la ocurrencia de los hechos. Así, por ejemplo, Lamb and Edgar-Smith encontraron que la edad promedio para la primera revelación era de 18 años. Esto resulta especialmente relevante si se toma en cuenta que la edad promedio para el inicio de los abusos en su muestra era de 8 años. ${ }^{3}$

Siendo estas las dificultades para la develación de los abusos, la sentencia alinea correctamente la dimensión jurídica, con la evidencia victimológica y epidemiológica de los abusos sexuales contra menores de edad. Luego, esta decisión, por la que se reconoce judicialmente que el reconocimiento del daño en estos casos es un proceso complejo que puede tomar años y décadas, reafirma la posibilidad para las víctimas de recibir reparación económica por los abusos sufridos.

II. En segundo lugar, el fallo acredita el daño hacia las víctimas por el hecho de la Iglesia de estar en conocimiento de los abusos y no haber tomado medidas al respecto.

${ }^{1}$ Sykes y MatZa, 1957, 664-670; Spraitz y Bowen, 2016, pp. 2515-2538.

2 Méndez y Montiel, 2016, pp. 53-81.

${ }^{3}$ Lamb y Edgar-Smith, 1994, pp. 307-326. Para el caso chileno, 60,9\% de la muestra de un estudio develó tardíamente los abusos, es decir, ocurrió al menos luego de seis meses después del inicio de los hechos abusivos. Al respecto ver: GutiÉrRez et al., 2016, pp. 1-15. 
Esto se desprende del considerando decimonoveno citado más arriba en donde se señala que el cese de la inactividad de la Iglesia marcó el punto desde el que se podía entender que la Iglesia dejó de infligir daño a las víctimas. En efecto, el fallo distingue el daño sufrido por las víctimas por el hecho de los abusos sexuales, del daño específico infringido a las víctimas por las omisiones y acciones sistemáticas de la jerarquía de la Iglesia Católica. Así lo establece al fijar el monto de la indemnización al señalar que daño moral indemnizable dice relación exclusivamente con el hecho propio de la Iglesia.

De esta manera, el fallo amplía la comprensión del daño en los abusos sexuales contra menores de edad. Entiende que el sufrimiento de las víctimas no se agota en el acto de abuso y que, parte importante de la profundización del daño y el trauma posterior, tiene que ver con la respuesta del entorno de las víctimas, de sus familias y de los contextos institucionales, eclesiales, estatales y de cualquier orden, que despliegan la organización y a sus representantes en función de neutralizar y desacreditar a las víctimas y los hechos ocurridos. Estas definiciones permiten reconocer jurisprudencialmente que el desamparo y el hecho por el que las víctimas tuvieron que enfrentarse a una institución que no solo no les creía, sino que llevó a cabo acciones explícitas de negación y difamación, es fuente fundamental de sufrimiento y dolor para las víctimas. En este sentido, el fallo parece ser un punto de inflexión y un gran avance jurisprudencial para entender la responsabilidad civil de las organizaciones. En efecto, el razonamiento de la Corte permite su aplicación a una gran diversidad de casos y tipos de instituciones en que, actuando con culpa organizacional, es decir, por medio de órganos de representación, ya sean individuales o colegiados, se genere daños a personas.

III. Un tercer elemento relevante es el reconocimiento jurídico de la Iglesia Católica chilena o en Chile y su representación en el obispo de Santiago. En este punto la decisión de la Corte de Apelaciones rompe una tradición que impedía la realización jurídica de la separación entre el Estado y la Iglesia Católica. Hasta entonces las normas y exegética canónica se imponía a cualquier razonamiento civil de los asuntos en que la Iglesia se viese envuelta. Como lo demuestran una importante cantidad de fallos previos $^{4}$, la lógica jurídica canónica parecía ser oponible al Estado chileno.

A consecuencia de lo anterior, la comprensión de la Iglesia como un ente "universal" como lo entiende el derecho canónico, convertía a la Iglesia Católica en una entidad impune si se toman en cuenta las evidentes dificultades para demandar a una organización cuya sede se encuentra en la ciudad del Vaticano y que no tiene representación jurídica aparente en Chile.

Luego, como resulta absurdo para el orden legal interno aceptar la impunidad de entidades por el hecho de autodeclararse "universales", el fallo correctamente entiende a la Iglesia Católica desde su estatus nacional, con una representación jurídica específica en el arzobispo de Santiago. El fallo hace referencia al propio derecho canónico para

${ }^{4}$ Fallo Casación Corte Suprema Rol N³640-04, 5 de enero de 2005; Fallo Ministro de Fuero Rol N¹-04, 5 de marzo 2005; Fallo Corte Apelaciones La Serena Rol N418-08, 26 diciembre 2008. 
demostrar que, incluso dentro de su propia comprensión, el Obispo es el representante y agente de la Iglesia Católica Universal. Establece, así, a los obispos en Chile como agentes de la Iglesia Católica chilena de manera que sus actos se encuentran bajo el derecho civil en su calidad representantes de la Iglesia por lo que lo hagan en el marco de sus funciones como obispos lo hacen "por" la Iglesia”. Esto, en cualquier caso, está prescrito explícitamente en los términos del Canon 393 del Código Canónico: "El Obispo diocesano representa la diócesis en todos los negocios jurídicos de la misma”.

Este reconocimiento, que, como se ha afirmado, termina de consolidar la separación entre el Estado y la Iglesia Católica chilena, es también una garantía futura que impide la indemnidad civil de la Iglesia cuando, concertadamente, genere daños a personas.

IV. En lo que constituye la parte central del fallo, se establece la posibilidad de entender a la Iglesia Católica como responsable por el hecho propio. Esta responsabilidad se funda, en los términos del fallo, en la culpa que como organización le cupo a la organización eclesial y sus representantes en la reacción frente a los abusos sexuales de uno de sus sacerdotes contra menores de edad. Esta posibilidad, que puede resultar novedosa jurisprudencialmente, es algo que para la doctrina chilena se encontraba fuera de cualquier discusión desde hace un tiempo. ${ }^{5}$ En efecto, toda persona jurídica, puede ser también sujeto pasivo de una acción de indemnización de perjuicios, siendo posible hacerla responsable por el hecho de sus dependientes o por el hecho propio. El último caso es aquel que se ha llamado la culpa en la organización, esto es, aquellas acciones u omisiones que "valorada como un proceso, infringe inequívocamente un deber de cuidado, aunque no sea posible determinar cuál elemento concreto de ese proceso fue determinante en la ocurrencia del daño". ${ }^{6}$ La culpa entonces no se localiza solo en un representante específico, sino en la función sistémica y general de la organización en cuestión. ${ }^{7}$ En este sentido, el razonamiento de la Corte de Apelaciones amplía las hipótesis de responsabilidad en un ámbito que, injustificadamente, ni siquiera consideraba la responsabilidad por el hecho de los sacerdotes entendidos como dependientes. ${ }^{8}$

Al establecer la posibilidad de hacer responsable a la Iglesia por la culpa de quienes actúan por ella, el fallo entiende de manera directa que parte de la cúpula eclesial fue responsable de la forma en que se enfrentaron y ocultaron los abusos. Sobre ello, la sentencia afirma en una primera oportunidad que los actos y omisiones de la Iglesia pueden ser calificados como propios de un encubrimiento. Inexplicablemente, el párrafo anterior fue reemplazado por la Corte de Apelaciones cambiando la palabra encubrimiento por ocultamiento, mediante un comunicado del Poder Judicial y no un acto procesal (http://www.pjud.cl/web/guest/noticias-del-poder-judicial/-/asset_publisher/

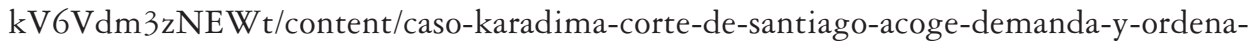

\footnotetext{
${ }^{5}$ Por todos, Barros. 2006, p. 193.

${ }^{6}$ Ibíd., p. 196.

${ }^{7}$ Hall, 2006, pp. 1-42.

${ }^{8}$ Incluso en casos de responsabilidad por el hecho del sacerdote, entendido como dependiente, la jurisprudencia había rechazado la responsabilidad de la Iglesia. Al respecto, VAras, 2005, pp. 241-253.
} 
a-la-iglesia-catolica-pagar-indemnizacion-a-victimas.) Aún así, los términos usados son penalmente equivalentes en tanto el ocultamiento es una de las hipótesis que dan pie al encubrimiento. Conforme con el numeral $2^{\circ}$ del artículo 17 del Código Penal: "son encubridores los que con conocimiento de la perpetración de un crimen o de un simple delito o de los actos ejecutados para llevarlo a cabo, sin haber tenido participación en él como autores ni como cómplices, intervienen, con posterioridad a su ejecución, de alguno de los modos siguientes: $2^{\circ}$ Ocultando o inutilizando el cuerpo, los efectos o instrumentos del crimen o simple delito para impedir su descubrimiento".

Independientemente del cambio en los términos usados, el fallo parece ser confuso cuando afirma, contradiciendo lo señalado más arriba, que no existen antecedentes suficientes en la causa para dar por probado el encubrimiento en cualquiera de sus formas. Asimismo, esta contradicción no es tal. Bajo los términos del fallo, su lógica parece decir que, si bien los actos de la jerarquía de la Iglesia entregan antecedentes que pueden ser calificados como encubrimiento u ocultamiento en un fallo posterior, los antecedentes aportados al juicio no permiten a su vez acreditar la participación criminal. Esto resulta obvio en la medida que los objetivos de un juicio de responsabilidad civil se alejan de aquellos de un juicio criminal, lo que no obsta a que puedan ser antecedentes probados que permitan, posteriormente, ser complementados por otros para satisfacer los estándares de prueba del proceso penal.

V. Si bien el fallo evita discutir el mérito de la responsabilidad por el hecho de sus dependientes solicitada como petición subsidiaria, sus considerandos establecen criterios jurídicos que permiten configurar la posibilidad de accionar contra la Iglesia, ya no por los actos que sistemáticamente puedan llevar a cabo sus representantes en el ejercicio de sus funciones, sino por los actos de los sacerdotes entendidos como dependientes y subordinados de la organización eclesial. De la lectura de los considerandos no queda duda que los términos empleados por los ministros no dejan lugar a dudas de que se está haciendo alusión a la subordinación civil por parte de sacerdotes respecto de sus obispos, es decir, de la relación de autoridad de los últimos sobre los primeros, mediante órdenes y guías de actuación.

De esta forma, y aunque el fallo parece confundir la eventual responsabilidad de la Iglesia por el hecho propio con la hipótesis de su responsabilidad por el hecho de sus sacerdotes, entrega los criterios que permiten pensar en la posibilidad de buscar reparación contra la Iglesia por los hechos de sus sacerdotes cuando no está comprometida la organización eclesial por actos de sus representantes y autoridades. Este reconocimiento jurisprudencial, con todo, parece ser evidente a la luz de la relación entre los obispos y sus sacerdotes y de las propias normas canónicas. ${ }^{9}$

VI. Las consideraciones anteriores permiten entender, por primera vez, un tratamiento respecto de la Iglesia Católica chilena como un sujeto de derecho sin privilegios (lo

\footnotetext{
${ }^{9}$ VARAs, 2005; Ferrer, 2005, pp. 557-608.
} 
contrario es posible ver en algunas decisiones: Fallo Casación Corte Suprema, 5.1.05, Rol 3640-04; Ministro de Fuero, 5.3.05 Rol 1-04; Corte Apelaciones La Serena, 26.12.08 Rol No 418-08). En efecto, la sentencia hace mención a las normas canónicas solo en la medida que permiten desvirtuar las alegaciones de la Iglesia. En lo central, le niega la posibilidad de oponer el derecho canónico al orden civil para desconocer realidades materiales (la Iglesia Católica en Chile) cuando tienen consecuencias jurídicas evidentes (su responsabilidad).

En términos doctrinarios, el fallo además permite distinguir tres niveles de responsabilidad cuando hablamos de abusos sexuales contra menores de edad en el contexto de la Iglesia Católica. En primer lugar, casos donde la organización eclesial se ve comprometida. Como el fallo muestra, para que esto proceda es necesario que se verifiquen actos u omisiones por parte de los representantes de esta, generando y profundizando los daños sobre las víctimas. En ellos, por tanto, reside la voluntad de la organización, para ello, la entrega de su dirección social no necesariamente tiene que ser formal, bastando que en los hechos así aparezca de manifiesto. ${ }^{10}$

En un segundo nivel, puede no estar comprometida la organización por no ser reconocible una culpa netamente organizacional. En estos casos la responsabilidad de la Iglesia puede buscarse ante la ausencia de la diligencia debida frente a la selección, formación y supervigilancia de sus subordinados y empleados. Estos son los casos en que surge la responsabilidad de la organización eclesial por los hechos de sus sacerdotes entendidos como dependientes.

Finalmente, existe aún la posibilidad de casos en que derechamente la responsabilidad institucional de la Iglesia no se vea comprometida porque no hubo actos reprochables por parte de la autoridades y representantes y porque se ejercieron las medidas de selección, supervisión y vigilancia adecuados frente a sus dependientes. En este caso, prevalece solamente la responsabilidad personal del sacerdote. Sin embargo, debido a la dinámica de los abusos sexuales en la Iglesia y los riesgos inherentes que conlleva la función pastoral, estos casos parecen ser realmente excepcionales. ${ }^{11}$

\section{Bibliografía}

BArros. Enrique, 2006: Tratado de Responsabilidad Extracontractual. Santiago: Editorial Jurídica de Chile.

FERrer, Javier, 2005. "La responsabilidad civil de la diócesis por los actos de sus clérigos", Ius Canonicum, XLV, No 90, páginas 557-608.

Frawley-O'Dea, Mary Gail, 2007: Perversion of power: Sexual abuse in the Catholic Church. Vanderbilt University Press.

\footnotetext{
${ }^{10}$ Pizarro, 2004; Barros, 2006.

${ }^{11}$ Frawley-O'Dea, 2007; Sartor, 2005, pp. 687-718.
} 
Gutiérrez, Carolina., Steinberg, Mónica y Capella, Claudia, 2016. "Develación de las Agresiones Sexuales: Estudio de Caracterización de Niños, Niñas y Adolescentes Chilenos”. Psykhe (Santiago), 25(2), 1-15.

HaLl, Margaret, 2006. "Institutional Tort Feasors: systemic negligence and the class action", Tort Law Journal. V14 No 2, 1-42.

LAMB, Sharon y Edgar-Smith, Susan, 1994. "Aspects of disclosure: Mediators of outcome of childhood sexual abuse”, Journal of Interpersonal Violence, 9(3), 307-326.

MÉndez, Xud y Montiel, Irene, 2016. "Factores inhibidores de la revelación de abuso sexual infantil", Revista de Victimología, (4), 53-81.

Pizarro, Carlos, 2004. "La responsabilidad civil de las personas sin fines de lucro", en Cuadernos de análisis jurídico. Colección Derecho privado $\mathrm{N}^{\circ} 1$.

SARTOR, Michael, 2005. "Respondeat Superior, Intentional Torts and clergy sexual misconduct: the implications of Fearing v. Bucher”, 62 Wask \& Lee. L. Rev. 687-718.

SPraItZ, Jason y Bowen, Kendra, 2016. "Techniques of neutralization and persistent sexual abuse by clergy: a content analysis of priest personnel files from the archdiocese of Milwaukee", Journal of interpersonal violence, 31(15), 2515-2538.

Sykes, Gresham y Matza, David, 1957. "Techniques of neutralization: A theory of delinquency”, American sociological review, 22(6), 664-670.

VARAs, Juan, 2005. "Sentencia sobre responsabilidad civil del obispo por los hechos de sus clérigos (Corte Suprema)”. Revista de derecho (Valdivia), 18(1), 241-253. 
